\title{
Primary research \\ An investigation of soy intake and mammographic characteristics in Hawaii
}

\author{
Gertraud Maskarinec and Lixin Meng
}

Cancer Research Center of Hawaii, Honolulu, Hawaii, USA

Correspondence: Gertraud Maskarinec, Cancer Research Center of Hawaii, 1236 Lauhala Street, Honolulu, HI 96813, USA. Tel: +1 808 586 3078; fax: +18085862984 e-mail: gertraud@crch.hawaii.edu

Received: 9 August 2000

Revisions requested: 19 September 2000

Revisions received: 13 October 2000

Accepted: 6 November 2000

Published: 5 January 2001
Breast Cancer Res 2001, 3:134-141

(C) 2001 Maskarinec and Meng, licensee BioMed Central Ltd (Print ISSN 1465-5411; Online ISSN 1465-542X)

\begin{abstract}
This cross-sectional investigation in Hawaii explored the relation between soy foods and mammographic characteristics using two food frequency questionnaires and a computer-assisted density assessment method. Japanese and Chinese women reported significantly greater soy food intake than Caucasian women. Whereas soy intake and the size of the dense areas were not related, soy intake and percent mammographic densities were positively associated. The size of the entire breast and the nondense area (ie the fatty part of the breast) were inversely related to soy intake. These results suggest the hypothesis that soy foods by themselves or as part of an Asian dietary pattern may affect the growth of the female breast before adulthood, but the possible mechanisms of action have to be explored in future studies.
\end{abstract}

Keywords: breast cancer, ethnicity, mammographic densities, nutrition, prevention, soy

\section{Synopsis}

Introduction: Based on ethnic [1] and international [2] differences in breast cancer risk, and on results from cell and animal studies [3], a role for soy foods in breast cancer prevention has been proposed. The epidemiologic investigations on soy and breast cancer risk have so far produced conflicting results [4-10]. Mammographic densities that refer to the distribution of fat, connective, and epithelial tissue in the female breast have been shown to be related to breast cancer risk [5]. A high percentage of dense parenchyma on mammographic images appears to confer a fourfold risk of developing breast cancer [11].

Aims: The purpose of this report is to investigate the hypothesis that soy foods are related to lower mammographic densities among a population of women with Caucasian, Chinese, Japanese, and Native Hawaiian ancestry living in Hawaii.

Methods: In a cross-sectional study approved by the institutional review boards of all participating institutions, women with different ethnic backgrounds were recruited at five mammography facilities on the island of Oahu. All study participants signed informed consent and completed a validated food frequency questionnaire (FFQ) [12] especially designed for a multiethnic population [13]. Because the FFQ included only two soy food items, we designed a soy questionnaire (SQ) with 10 categories of soy foods that are commonly consumed in Hawaii: tofu, fried tofu, pressed tofu, green soybeans, miso, soybean sprouts, tofu skin, soy milk/drink, vegetarian meats, and fermented soybeans. Intake of soy foods according to the SQ in a validation study among 102 women was highly correlated with urinary isoflavone excretion [14].

Both cranio-caudal views of the mammogram were obtained from the mammography clinics after the radiologic evaluation had been completed and any malignancy or suspicious lesions ruled out. Women who reported a history of breast cancer or augmentation surgery were excluded from the study. Computer-assisted mammographic density assessment was performed using a method that was first developed in Toronto

$\mathrm{BMI}=$ body mass index $; \mathrm{Cl}=$ confidence interval; $\mathrm{FFQ}=$ food frequency questionnaire $;$ icc $=$ intraclass correlation coefficients; $\mathrm{SQ}=$ soy questionnaire; $\kappa_{\mathrm{w}}=$ weighted Kappa statistics. 
[15] and later modified at the University of Southern California in Los Angeles [16]. The reader first draws the outline of the breast (using an outlining tool) and then searches for the best threshold gray level value $X$ where all pixels with values above $X$ are considered to represent mammographic densities. The pixel count corresponding to the area colored within the outline of the breast is determined by the computer, as is the total area within the outline of the breast. We used four mammographic parameters for analysis: breast area (total area within the outline of the breast), dense area (colored area), percent densities (the ratio of dense area and breast area), and the nondense area (the difference between the breast area and the dense area). Body mass index (BMI) was computed using the formula weight $(\mathrm{kg})$ divided by the height $\left(\mathrm{m}^{2}\right)$. We calculated intraclass correlation coefficients (icc) and weighted Kappa statistics $\left(\kappa_{\mathrm{w}}\right)$ using quartile ranking to compare dietary intake from the two questionnaires. After adjustment for total energy intake using the residual method [17], we computed means for the mammographic parameters by quartile of soy intake. Trend tests regressing the mean of each category on soy intake were performed to investigate a possible relation between soy intake and the mammographic parameters. Multiple linear regression with a stepwise selection procedure was applied to explore the relation of soy intake, $\mathrm{BMl}$, and reproductive factors with mammographic parameters.

Results: Complete data were available for 514 women, of whom more than one-half were postmenopausal (Table 1). Mean soy food intake was considerably higher according to the $\mathrm{SQ}$ than the FFQ, but the estimates from the two instruments were highly correlated. The icc for all soy foods combined was 0.70 (95\% confidence interval $[\mathrm{Cl}], 0.59-0.77)$ and $\kappa_{\mathrm{w}}$ was $0.71(95 \% \mathrm{Cl}, 0.66-0.76)$. The same was true for tofu intake from the SQ and the FFQ: the icc was $0.82(95 \% \mathrm{Cl}$, $0.79-0.85)$ and $\kappa_{w}$ was $0.77(95 \% \mathrm{Cl}, 0.73-0.81)$. The means of tofu intake for each ethnic group, as estimated from the two dietary instruments, were very similar. We observed considerable ethnic differences in the consumption of meat, rice, alcohol, and soy foods (Table 1). Counting all soy foods, Chinese and Japanese women reported nearly twice as high an intake as Caucasian women. Native Hawaiian women had the highest BMI, the greatest caloric intake, and consumed more soy foods than the Asian women. Tofu and soy milk/drinks were the most commonly reported soy foods. Green soybeans and soybean sprouts were eaten in moderate amounts, whereas the other products, miso, tofu skin, Western vegetarian meats, and fermented soybeans, were reported infrequently.

All mammographic parameters (Table 1) except the size of the dense area were statistically significantly different by ethnicity $(P<0.001)$. Breast area, nondense area, and percent densities showed a significant trend by calorie adjusted quartiles of soy intake (Table 2). The average breast area and the nondense area were approximately $25 \%$ smaller among women in the highest soy intake category than among women in the lowest category, whereas percent densities were $11 \%$ greater with higher soy intake. The dense area appeared to be slightly smaller with increasing soy intake, but the trend test was not significant. We observed no significant trends in the Chinese and Japanese women after we stratified by ethnic group. Dense area and percent densities among Caucasian and Native Hawaiian women showed a positive relation with soy intake. In a linear regression model, we observed a weak association between calorie adjusted soy intake and percent densities (partial regression coefficient $b=0.009, P=0.004$ ) after adjustment for age, BMI, parity, and family history of breast cancer. On the contrary, the size of the nondense area (ie the fatty part of the breast) was inversely related to soy intake after adjustment for $\mathrm{BMI}$, age, and parity $(b=-0.06, P=0.002)$.

Discussion: This study among healthy pre- and postmenopausal women who participated in mammography screening detected an inverse relation between self-reported soy food intake and the size of the breast, in particular the nondense area, as measured in mammographic images. Contrary to our hypothesis, we detected a positive association between soy intake and percent densities, and also higher levels of percent densities among Chinese and Japanese women who are at lower risk for breast cancer. This could be interpreted as evidence that soy increases breast cancer risk as a result of its estrogenic effects [3]. However, an alternate explanation may be that the size of the nondense area, which is inversely related to soy, is important in determining breast cancer risk. Mammary gland mass [18] has been proposed as a risk factor for breast cancer because of the higher number of ductal stem cells that develop as a result of intrauterine influences and high energy intake early in life. Although we did not collect information on childhood soy consumption, we wish to propose that soy foods, either by themselves or as part of a Asian dietary pattern characterized by low fat, high cereal, low dairy and low red meat intake, may contribute to the ethnic differences in mammographic characteristics. The importance of childhood nutrition for adult anthropometric measures is supported by comparative growth studies [19].

The finding of a nutritional effect on breast development before puberty agrees with the results from migrant studies demonstrating that it takes two or more generations to increase breast cancer risk. The time lag indicates that only descendants of the migrants who were born and who grew up in the host country will develop a similar risk as the host population, and that possible causes act early in life or in utero [20]. Evidence exists in addition to suggestions from migration studies that exposures during the perinatal period and adolescence are important for breast cancer risk later in life. A Western diet, as opposed to an Asian diet, may lead to increased body fat mass [3,21] during preadolescence mediated through more available sex steroids. Alternatively, the high soy content of Asian diets may inhibit the secretion of sex steroids and its effects on body fat through the antiestrogenic effects of isoflavones [22].

We purposefully did not adjust our analyses for ethnicity because we wished to explore nutritional factors that may determine the ethnic differences. The advantage of including several ethnic groups with different dietary habits was a greater 
Table 1

\begin{tabular}{|c|c|c|c|c|c|c|c|c|}
\hline \multirow[b]{2}{*}{ Characteristic } & \multirow[b]{2}{*}{ Caucasian } & \multirow[b]{2}{*}{ Chinese } & \multirow[b]{2}{*}{ Japanese } & \multirow{2}{*}{$\begin{array}{c}\text { Native } \\
\text { Hawaiian }\end{array}$} & \multirow[b]{2}{*}{ Others } & \multicolumn{2}{|c|}{ All } & \multirow[b]{2}{*}{$P^{\star}$} \\
\hline & & & & & & Mean & SD & \\
\hline Number & 182 & 72 & 157 & 63 & 40 & 514 & & 0.001 \\
\hline Age (years) & 54.1 & 56.8 & 53.3 & 52.7 & 51.8 & 53.9 & 10.1 & 0.064 \\
\hline Body mass index & 25.3 & 22.8 & 23.2 & 30.3 & 25.4 & 24.9 & 5.8 & 0.001 \\
\hline Years of education & 16.1 & 16.7 & 16.1 & 14.6 & 14.1 & 15.8 & 3.1 & 0.001 \\
\hline Family history of breast cancer (\%) & 14.3 & 9.7 & 13.4 & 14.3 & 14.3 & 13.0 & & 0.848 \\
\hline Age at menarche (years) & 12.5 & 12.2 & 12.2 & 12.4 & 12.8 & 12.4 & 1.5 & 0.130 \\
\hline Age at first live birth (years) & 24.9 & 26.7 & 27.0 & 21.6 & 24.4 & 25.3 & 5.3 & 0.001 \\
\hline Percent postmenopausal & 59.9 & 63.9 & 55.4 & 55.6 & 60.0 & 58.6 & & 0.757 \\
\hline Daily caloric intake (kcal) & 2022 & 1806 & 2020 & 2886 & 2766 & 2155 & 1413 & 0.001 \\
\hline Percent calories from fat (\%) & 30.3 & 27.5 & 29.6 & 31.0 & 31.7 & 29.9 & 6.4 & 0.003 \\
\hline Fruits and vegetables (servings/day) & 5.5 & 5.2 & 5.1 & 6.9 & 6.4 & 5.6 & 4.2 & 0.212 \\
\hline Meat (g/day) & 86.9 & 87.9 & 100.1 & 145.5 & 169.3 & 104.7 & 100.2 & 0.001 \\
\hline Rice (g/day) & 89.5 & 206.5 & 240.3 & 206.8 & 258.5 & 179.5 & 163.6 & 0.001 \\
\hline Alcohol (g/day) & 111.7 & 32.4 & 27.0 & 76.7 & 74.2 & 67.5 & 185.5 & 0.001 \\
\hline All soy foods (SQ) (g/day) & 22.3 & 37.6 & 39.4 & 51.9 & 72.4 & 37.2 & 86.3 & 0.001 \\
\hline All soy foods (FQ) (g/day) & 10.6 & 20.7 & 27.2 & 25.7 & 24.3 & 20.0 & 32.2 & 0.001 \\
\hline All tofu (SQ) (g/day) & 8.6 & 18.6 & 21.0 & 26.8 & 14.2 & 16.4 & 31.9 & 0.001 \\
\hline Tofu (FFQ) (g/day) & 9.2 & 18.9 & 24.4 & 23.8 & 22.1 & 18.0 & 30.7 & 0.001 \\
\hline Soy milk/drinks (SQ) (g/day) & 7.4 & 6.3 & 5.6 & 4.7 & 29.1 & 8.1 & 45.9 & 0.005 \\
\hline Green soybeans (SQ) (g/day) & 1.4 & 2.6 & 4.8 & 9.2 & 6.2 & 3.9 & 16.2 & 0.001 \\
\hline Soybean sprouts (SQ) (g/day) & 1.3 & 1.6 & 1.9 & 6.0 & 4.9 & 2.4 & 6.9 & 0.001 \\
\hline Other soy foods (SQ) (g/day) & 3.7 & 8.5 & 6.1 & 5.2 & 17.9 & 6.4 & 25.7 & $<0.001$ \\
\hline Breast area ( $10^{3}$ pixels) & 1209 & 807 & 789 & 1353 & 1146 & 1037 & 588 & $<0.001$ \\
\hline Dense area ( $10^{3}$ pixels) & 296 & 246 & 254 & 307 & 304 & 278 & 171 & 0.460 \\
\hline Mammographic percent density (\%) & 29.0 & 36.0 & 34.9 & 26.4 & 31.2 & 31.6 & 16.9 & $<0.001$ \\
\hline Nondense area ( $10^{3}$ pixels) pixels) & 914 & 561 & 535 & 1046 & 842 & 759 & 557 & $<0.001$ \\
\hline
\end{tabular}

FFQ, Food frequency questionnaire; SQ, soy questionnaire. *Probabilities for ethnic differences were obtained through either one-way analysis of variance or chi-square tests.

variability in soy intake than could ever be found in an ethnically homogeneous population. The higher percent densities among Asian women do not necessarily contradict the mammographic density hypothesis. It appears from a case-control study [23] that the relation between percent densities and breast cancer is of similar strength in women of different ethnicities, although density levels vary by ethnicity.

Because of the lack of a lifetime history of soy intake in our study, we do not know whether soy consumption during early life when breast development occurred was similar to the current intake. Caucasian women who reported soy intake probably started eating these foods later in life and not during childhood. Soy may therefore have not had the opportunity to influence the appearance of their mammograms. Soy consumption, however, may be a marker for Chinese and Japanese ethnicity; an indicator for childhood nutritional patterns that include, but are not limited to, soy foods. These dietary patterns may explain some of the anthropometric characteristics found in adult women.

In conclusion, this examination of mammographic characteristics detected some associations with soy foods that suggest an influence of nutritional patterns on the development 


\begin{tabular}{|c|c|c|c|c|c|}
\hline & \multirow{2}{*}{$\begin{array}{c}\text { All }(n=514) \\
\text { Mean }\end{array}$} & \multicolumn{2}{|c|}{ Chinese/Japanese } & \multicolumn{2}{|c|}{ Caucasian/Hawaiian } \\
\hline & & $n$ & Mean & $n$ & Mean \\
\hline \multicolumn{6}{|l|}{ Breast area ( $10^{3}$ pixels) } \\
\hline \multicolumn{6}{|l|}{ Soy foods } \\
\hline$\leq 6.7 \mathrm{~g}$ & 1193 & 26 & 808 & 88 & 1297 \\
\hline$>6.7-18.5 \mathrm{~g}$ & 1001 & 56 & 786 & 67 & 1166 \\
\hline$>18.5-34.8 \mathrm{~g}$ & 1034 & 71 & 830 & 50 & 1261 \\
\hline$>34.8 \mathrm{~g}$ & 921 & 76 & 763 & 40 & 1252 \\
\hline$P_{\text {trend }}$ & 0.06 & & 0.96 & & 0.56 \\
\hline \multicolumn{6}{|l|}{ Dense area ( $10^{3}$ pixels) } \\
\hline \multicolumn{6}{|l|}{ Soy foods } \\
\hline$\leq 6.7 \mathrm{~g}$ & 296 & 26 & 258 & 88 & 294 \\
\hline$>6.7-18.5 \mathrm{~g}$ & 267 & 56 & 246 & 67 & 287 \\
\hline$>18.5-34.8 \mathrm{~g}$ & 282 & 71 & 266 & 50 & 309 \\
\hline$>34.8 \mathrm{~g}$ & 266 & 76 & 240 & 40 & 313 \\
\hline$P_{\text {trend }}$ & 0.98 & & 0.49 & & 0.05 \\
\hline \multicolumn{6}{|l|}{ Percent densities } \\
\hline \multicolumn{6}{|l|}{ Soy foods } \\
\hline$\leq 6.7 \mathrm{~g}$ & 30.0 & 26 & 38.2 & 88 & 26.7 \\
\hline$>6.7-18.5 \mathrm{~g}$ & 30.9 & 56 & 34.3 & 67 & 28.9 \\
\hline$>18.5-34.8 \mathrm{~g}$ & 32.2 & 71 & 35.6 & 50 & 28.8 \\
\hline$>34.8 \mathrm{~g}$ & 33.4 & 76 & 34.5 & 40 & 30.7 \\
\hline$P_{\text {trend }}$ & 0.04 & & 0.31 & & 0.06 \\
\hline \multirow{2}{*}{\multicolumn{6}{|c|}{$\begin{array}{l}\text { Nondense area ( } 10^{3} \text { pixels) } \\
\text { Soy foods }\end{array}$}} \\
\hline \multicolumn{4}{|c|}{ Soy foods } & & \\
\hline$\leq 6.7 \mathrm{~g}$ & 897 & 26 & 550 & 88 & 1003 \\
\hline$>6.7-18.5 \mathrm{~g}$ & 734 & 56 & 540 & 67 & 879 \\
\hline$>18.5-34.8 \mathrm{~g}$ & 753 & 71 & 564 & 50 & 952 \\
\hline$>34.8 \mathrm{~g}$ & 655 & 76 & 523 & 40 & 939 \\
\hline$P_{\text {trend }}$ & 0.04 & & 0.65 & & 0.32 \\
\hline
\end{tabular}

of the female breast. What implications, if any, these findings have for breast cancer risk has to be determined in prospective or interventions studies that will investigate possible mechanisms of actions, such as hormone levels, differences in estrogen metabolism, other dietary parameters, and genetic polymorphisms.

\section{Full article}

\section{Introduction}

Breast cancer risk differs greatly by ethnicity. The US breast cancer incidence rates per 100,000 women in 1988-1992 [1] (invasive cases only, age-adjusted to 1970 US population) were 112 for Caucasian women, 106 for Native Hawaiian women, 82 for Japanese women, and 55 for Chinese women. Incidence rates between 23 and 31 per 100,000 (age-adjusted to the World Standard population) have been reported in Japan [2] for the same period. The role of isoflavones contained in soy products, based on these risk differences and on results from cell and animal studies [3], has been investigated in breast cancer prevention and produced conflicting results. A case-control study among Asian-American women [4] detected a $30 \%$ decreased risk of pre- and post- menopausal women breast cancer for women who reported eating tofu more than once a week as compared with women who ate tofu less than once a month. In a study from Singapore [5,6], consumption of $55 \mathrm{~g}$ or more soy products per day was protective in premenopausal but not in postmenopausal women. Studies from China [7] and Japan [8] did not detect a protective effect of soy intake. However, two recent studies reported a lower breast cancer risk with increasing isoflavonoid excretion in urine $[9,10]$.

Mammographic densities that refer to the distribution of fat, connective, and epithelial tissue in the female breast have been shown to be related to breast cancer risk [11]. These densities are not abnormalities, but variations of 
healthy breast tissue. Fat appears dark on mammograms, whereas the radiographically light areas representing epithelial and connective tissue are relevant to breast cancer risk. A high percentage of dense parenchyma on mammographic images, $50-75 \%$ as compared with $0-10 \%$ of densities depending on the study, appears to confer a fourfold risk of developing breast cancer [11]. The purpose of this report is to investigate the hypothesis that soy foods are related to lower mammographic densities among a population of women with Caucasian, Chinese, Japanese, and Native Hawaiian ancestry living in Hawaii.

\section{Materials and methods Recruitment and data collection}

In a cross-sectional study design, women receiving annual screening mammograms were recruited at five mammography facilities on the island of Oahu. These clinics together provide more than one-half of all mammograms on the island (Cancer Research Center of Hawaii, unpublished data). As a result of greater than $90 \%$ insurance coverage among Hawaii's population [24] and a 1991 legislative mandate for health plans to cover annual screening mammography for women aged 40 years and older, selfreported mammography utilization [25] has been greater than $70 \%$. Participation has been similar among Caucasian, Native Hawaiian, and Japanese women [25]. The Committee on Human Subjects at the University of Hawaii and the research boards of all participating institutions approved the study protocol. Women who did not speak English, women who reported a history of breast cancer or augmentation surgery, and women with suspicious lesions on the mammograms were excluded from the study, but women taking oral contraceptives and hormone replacement therapy were eligible to participate.

\section{Dietary data collection}

All study participants signed informed consent and completed a validated FFQ [12] especially designed for a multiethnic population [13]. The FFQ was self-administered and processed by optical scanning. The goal, as described in detail elsewhere [12,13], was to include a sufficient number of food items so that at least $85 \%$ of the intake for nutrients of interest was captured. Analyses were performed to estimate intakes of 130 macro- and micronutrients for every study participant. Basic nutrient data from the US Department of Agriculture [26] has been supplemented and continuously updated with information from local recipes that are consumed by the different ethnic groups in Hawaii. Unpublished data also found acceptable validity for Native Hawaiian women, in addition to a published calibration study [12] that included Caucasian and Japanese women. Because the FFQ included only two soy food items, one each for tofu and Western vegetarian meats, we designed an additional SQ with 10 categories of soy foods commonly consumed in Hawaii: tofu, fried tofu, pressed tofu, green soybeans, miso, soybean sprouts, tofu skin, soy milk/drink, vegetarian meats, and fermented soybeans. Intake of soy foods according to the SQ in a validation study among 102 women was highly correlated with urinary isoflavone excretion [14].

\section{Mammogram density assessment}

All participating mammography clinics were accredited by the Food and Drug Administration and by the American College of Radiology. Mammography was performed on dedicated mammographic units with high contrast mammographic film and dedicated film processing. All mammograms for this study were therefore of comparable quality. Both cranio-caudal views of the mammogram were obtained from the mammography clinics after the radiologic evaluation had been completed and any malignancy ruled out. The films were scanned into a PC using an X-ray digitizer (Cobrascan CX-612-T, Radiographic Digital Imaging, Compton, CA, USA) at a resolution of 300 dots per inch. Computer-assisted mammographic density assessment was performed using a method that was first developed in Toronto [15] and later modified at the University of Southern California in Los Angeles [16]. The reader first draws the outline of the breast (using an outlining tool) and then searches for the best threshold gray level value $X$ where all pixels with values above $X$ are considered to represent mammographic densities. The pixel count corresponding to the area colored within the outline of the breast is determined by the computer, as is the total area within the outline of the breast. The readers were blinded to the identity of the subjects and to the clinic where the mammogram was taken. The correlation coefficient between the two readers for the readings of the size of the dense areas was 0.92. Four mammographic parameters were used for analysis: breast area (total area within the outline of the breast), dense area (colored area), percent densities (the ratio of dense area and breast area), and the nondense area (the difference between the breast area and the dense area).

\section{Statistical analysis}

We transformed non-normally distributed variables such as breast area, dense area, and calories using their natural logarithms. BMI was computed using the formula weight $(\mathrm{kg})$ divided by the height $\left(\mathrm{m}^{2}\right)$. Because breast cancer risk is low for Japanese and Chinese women and high in Caucasian and Native Hawaiian women, we divided the population into these two groups for analysis. The small number of women did not allow analysis for every ethnic group individually. The reason for including different ethnic groups into this study was, more importantly, to increase variability in exposure (ie soy intake) not to study the effect of soy foods in each ethnic group separately. We calculated icc and $\kappa_{w}$ values [27] using quartile ranking to compare dietary intake from the two questionnaires. A categorical soy intake variable was created based on quartiles of the 
calorie adjusted soy intake as measured by the SQ. Adjustment for total energy intake used the residual method [17]. After entering soy intake into a regression model as the dependent variable and calories as the independent variable, we added the residuals from this model to the median caloric intake and to the intercept to obtain adjusted intake estimates. We then computed arithmetical means for the mammographic parameters by quartile of soy intake. Trend tests regressing the mean of each category on soy intake were performed to investigate a possible relation between soy intake and the mammographic parameters. Multiple linear regression with a stepwise selection procedure [28] was applied to explore the relation of soy intake, BMI, and reproductive factors with mammographic parameters. All analyses were performed using PC-SAS ${ }^{\circledR}$, release 6.12 (SAS Institute, Cary, NC, USA).

\section{Results}

\section{Dietary intake}

Complete data were available for 514 women, of whom more than one-half were postmenopausal. Caucasian and Japanese women represented the largest groups in this study (Table 1). Educational achievement was fairly high across all ethnic groups. BMI and daily caloric intake were highest among Native Hawaiian women, and lowest among Chinese and Japanese women. Mean soy food intake was considerably higher according to the $\mathrm{SQ}$ than the FFQ, but the estimates from the two instruments were highly correlated. The icc for all soy foods combined was $0.70(95 \% \mathrm{Cl}, 0.59-0.77)$ and $\kappa_{\mathrm{w}}$ was $0.71(95 \% \mathrm{Cl}$, $0.66-0.76)$. The same was true for tofu intake from the $\mathrm{SQ}$ and the FFQ: the icc was $0.82(95 \% \mathrm{Cl}, 0.79-0.85)$ and $\kappa_{w}$ was $0.77(95 \% \mathrm{Cl}, 0.73-0.81)$. The means of tofu intake as estimated from the two dietary instruments were very similar for each ethnic group.

We observed considerable ethnic differences in the consumption of meat, rice, alcohol, and soy foods. Whereas Caucasians consumed more alcohol than all other groups, they reported the lowest rice and soy intake. Interestingly, meat intake was equally low in Caucasian as in Chinese women. Chinese and Japanese women reported nearly twice as high an intake as Caucasian women, counting all soy foods. The Native Hawaiian group, however, consumed even more soy foods than did the Asian women. Tofu and soy milk/drinks were the most commonly reported soy foods. Green soybeans and soybean sprouts were eaten in moderate amounts, whereas the other products, miso, tofu skin, Western vegetarian meats, and fermented soybeans, were reported infrequently.

\section{Mammographic characteristics}

All mammographic parameters (Table 1) except the size of the dense area were statistically significantly different by ethnicity $(P<0.001)$. Breast area and nondense area were considerably larger among Caucasian and Native
Hawaiian women than among Chinese and Japanese women. Although the dense areas were slightly smaller among women of Asian descent, their percent densities were greater than for Caucasian and Native Hawaiian women because of the smaller breast area among women of Asian descent.

\section{Soy intake and mammographic characteristics}

Breast area, nondense area, and percent densities showed a significant trend by calorie adjusted quartiles of soy intake (Table 2). The average breast area and the nondense area were approximately 25\% smaller among women in the highest soy intake category than among women in the lowest category, whereas percent densities were $11 \%$ greater with higher soy intake. The dense areas appeared to be slightly smaller with increasing soy intake, but the trend test was not significant. We observed no significant trends in the Chinese and Japanese women after we stratified by ethnic group. Dense areas and percent densities among Caucasian and Native Hawaiian women showed a weak positive relation with soy intake. Excluding women who reported less than 800 calories or more than 4000 calories did not change these results substantially. We obtained similar results in a linear regression model with adjustment for confounding variables. Whereas we did not observe a relation between soy intake and the size of the dense areas, we found an association between calorie adjusted soy intake and percent densities $(b=0.009, P=0.004)$ after adjustment for age, BMl, parity, and family history of breast cancer. On the contrary, the size of the nondense area (ie the fatty part of the breast) was inversely related to soy intake after adjustment for BMl, age, and parity $(b=-0.06$, $P=0.002)$. The effects were in the same direction for preand postmenopausal women, but they were stronger for postmenopausal women.

\section{Discussion}

This study among healthy pre- and postmenopausal women who participated in mammography screening detected an inverse relation between self-reported soy food intake and the size of the breast, in particular the nondense area, as measured in mammographic images. Contrary to our hypothesis, we detected a positive association between soy intake and percent densities, and also higher levels of percent densities among Chinese and Japanese women who are at lower risk for breast cancer. This could be interpreted as evidence that soy increases breast cancer risk as a result of its estrogenic effects [3]. An alternative explanation, however, may be that the size of the nondense areas, which is inversely related to soy, is important in determining breast cancer risk. Mammary gland mass [18] has been proposed as a risk factor for breast cancer because of the higher number of ductal stem cells that develop as a result of intrauterine influences and high energy intake early in life. Although we did 
not collect information on childhood soy consumption, we wish to propose that soy foods, either by themselves or as part of an Asian dietary pattern characterized by low fat, high cereal, low dairy and low red meat intake, may contribute to the ethnic differences in mammographic characteristics. Dietary patterns, as shown in several publications $[29,30]$, can be identified from nutritional information using factor analysis. We purposefully did not adjust our analyses for ethnicity because we wished to explore nutritional factors that may determine the ethnic differences.

We hypothesize, as a possible mechanism of how soy intake may affect mammographic characteristics, that soy intake during developmental years may be responsible for the smaller fat component of the breast through an effect of soy on the growth of the female breast during that period. The importance of childhood nutrition for adult anthropometric measures is supported by comparative growth studies [19]. A nutritional effect on breast development before puberty agrees with the results from migrant studies demonstrating that it takes two or more generations to increase breast cancer risk [31,32]. The time lag indicates that only descendants of the migrants who were born and who grew up in the host country will develop a similar risk as the host population, and that possible environmental and behavioral causes act early in life or in utero [20]. In addition to suggestions from migration studies, evidence exists that exposures during the perinatal period and adolescence are important for breast cancer risk later in life. The occurrence of high risk mammographic patterns, for example, was associated with the weight of the placenta, the main estrogen-producing organ during pregnancy [33]. A Western diet, as opposed to an Asian diet, may lead to increased body fat mass $[3,21]$ during preadolescence, mediated through more available sex steroids. The high soy content of Asian diets may alternatively inhibit the secretion of sex steroids and its effects on body fat through the antiestrogenic effects of isoflavones [22].

The higher percent densities among Asian women do not necessarily contradict the mammographic density hypothesis. It appears from a recent case-control study [23] that the relation between percent densities and breast cancer is of similar strength in women of different ethnicities although density levels vary by ethnicity. Although the relation of soy intake and mammographic densities has not been investigated previously, several dietary studies have shown weak associations between micro- and macronutrients and mammographic densities. Energy-adjusted saturated fat intake was positively related, and fiber and carotenoids were inversely related to mammographic densities in a case-control study [34]. Areas of density decreased by $6.1 \%$ in the intervention group, as compared with $2.1 \%$ in the control group, during a low fat intervention [35]. Lower cholesterol and saturated fat intake, in particular, predicted a decrease in mammographic density [36]. Higher fat intake [37] and high density lipoprotein cholesterol levels [38] were related to denser mammographic patterns, suggesting that breast cancer risk may be related to blood lipid levels. Small differences in mammographic densities across levels of vitamin $B_{12}, C$, and $E$ as well as polyunsaturated fat intake were described recently [39] from a large cohort of Caucasian women.

Differences in the quality of films between clinics and subjects may have introduced some measurement error. To minimize the subjective component of the assessment method, we spent much effort in training the readers and compared the results between the readers frequently. The high correlation coefficient indicates a high level of standardization in mammographic assessment. Given the measurement errors in dietary and mammographic density assessment, the multi-factorial determination of mammographic densities, and the recall bias inherent to all dietary studies, it is difficult to identify a small effect. Because the soy food relation was the primary aim in the proposal for this study, we did not search for positive results among a multitude of food items, but focused on the soy hypothesis.

The lack of a lifetime history of soy intake and the crosssectional design limit our study's ability to establish causal relations. The dietary assessment asked only about intake during the past year. We therefore do not know whether soy consumption during earlier life when breast development occurred was similar to the current intake. Because Caucasian women who reported soy intake probably started eating these foods later in life and not during childhood, soy may have not had the opportunity to influence the appearance of their mammograms. Soy consumption may, however, be a marker for Chinese and Japanese ethnicity; an indicator for childhood nutritional patterns that include, but are not limited to, soy foods. These dietary patterns may explain some of the anthropometric characteristics found in adult women.

One strength of this study was the opportunity to investigate women with different ethnicity living in a similar environment that has a variety of foods available to persons with all ancestries. The advantage of including several ethnic groups with different dietary habits was a greater variability in soy intake than could ever be found in an ethnically homogeneous population. Because $91 \%$ of study participants were born in the United States, the majority of women also lived through adolescence under similar conditions. The comparable socioeconomic status and equal access to mammography screening among women with Caucasian and Asian ancestry also offered a unique opportunity to compare mammographic parameters. In conclusion, this examination of mammographic characteristics detected some associations with soy foods that 
suggest an influence of nutritional patterns on the development of the female breast. What implications, if any, these findings have for breast cancer risk has to be determined in prospective or interventions studies that will investigate possible mechanisms of actions, such as hormone levels, differences in estrogen metabolism, other dietary parameters, and genetic polymorphisms.

\section{Acknowledgements}

The authors greatly appreciate the time and effort contributed by the participating women. We are grateful to Giske Ursin and Mel Astrahan at the University of Southern California for the use of Image Analyst, the mammographic density assessment software package. The authors also thank Li-Ching Lyu for her data from the pilot study. This research was supported by the US Army Medical Research and Material Command under DAMD17-96-1-6284, by $\mathrm{NIH}$ grant 5-K12 CA 01708, and by ACS grant IRG-92-025-IRG.

\section{References}

1. Miller BA, Kolonel LN, Bernstein L, Young JJL, Swanson GM, West D, Key CR, Liff JM, Glover CS, Alexander GA: Racial/Ethnic Patterns of Cancer in the United States 1988-1992, NIH Publication No 96-4104. Bethesda, MD: National Cancer Institute, 1996.

2. Parkin DM, Whelan SL, Ferlay J, Raymond L, Young J (Eds): C15VII: Electronic Database of Cancer Incidence in Five Continents, vol VII, IARC Scientific Publications No 143. Lyon, France: International Agency for Research on Cancer, 1997.

3. Adlercreutz H: Western diet and Western diseases: some hormonal and biochemical mechanisms and associations. Scand $J$ Clin Lab Invest 1990, 2014:3-23.

4. Wu AH, Ziegler RG, Horn-Ross PL, Nomura AMY, West DW, Kolonel LN, Rosenthal JF, Hoover RN, Pike MC: Tofu and risk of breast cancer in Asian-Americans. Cancer Epidemiol Biomarkers Prev 1996, 5:901-906.

5. Lee HP, Gourley L, Duffy SW, Esteve J, Lee J, Day NE: Dietary effects on breast-cancer risk in Singapore. Lancet 1991, 337: 1197-1200.

6. Lee HP, Gourley L, Duffy SW, Estève J, Lee J, Day NE: Risk factors for breast cancer by age and menopausal status: a case-control study in Singapore. Cancer Causes Control 1992, 3:313-322.

7. Yuan JM, Wang Q-S, Ross RK, Henderson BE, Yu MC: Diet and breast cancer in Shanghai and Tianjin, China. $\mathrm{Br} J$ Cancer 1995, 71:1353-1358.

8. Hirose K, Tajima K, Hamajima N, Inoue M, Takezaki T, Kuroishi T, Yoshida M, Tokudome S: A large-scale, hospital-based case-control study of risk factors of breast cancer according to menopausal status. Jpn J Cancer Res 1995, 86:146-154.

9. Ingram D, Sanders K, Kolybaba M, Lopez D: Case-control study of phyto-oestrogens and breast cancer. Lancet 1997, 350: 990-997.

10. Zheng W, Dia Q, Custer LJ, Shu X-O, Wen W-Q, Jin F, Franke AA: Urinary excretion of isoflavonoids and the risk of breast cancer. Cancer Epidemiol Biomarkers Prev 1999, 8:35-40.

11. Boyd NF, Lockwood GA, Byng JW, Tritchler DL, Yaffe MJ: Mammographic densities and breast cancer risk. Cancer Epidemiol Biomarkers Prev 1998, 7:1133-1144.

12. Stram DO, Hankin JH, Wilkens LR, Henderson B, Kolonel LN: Calibration of the dietary questionnaire for a multiethnic cohort in Hawaii and Los Angeles. Am J Epidemiol 2000, 151:358-370.

13. Kolonel LN, Henderson BE, Hankin JH, Nomura AMY, Wilkens LR, Pike MC, Stram DO, Monroe KR, Earle ME, Nagamine FS: A multiethnic cohort in Hawaii and Los Angeles: baseline characteristics. Am J Epidemio/ 2000, 151:346-357.

14. Maskarinec G, Singh S, Meng L, Franke AA: Dietary soy intake and urinary isoflavone excretion among women from a multiethnic population. Cancer Epidemiol Biomarkers Prev 1998, 7: 613-619.

15. Byng JW, Boyd NF, Fishell E, Jong RA, Yaffe MJ: The quantitative analysis of mammographic densities. Phys Med Biol 1994, 39:1629-1638.
16. Ursin G, Astrahan MA, Salane M, Parisky YR, Pearce JG, Daniels JR, Pike MC, Spicer DV: The detection of changes in mammographic densities. Cancer Epidemiol Biomarkers Prev 1998, 7: 43-47.

17. Willett W: Nutritional Epidemiology, edn 2. New York: Oxford University Press, 1998:288.

18. Trichopoulos D, Lipman RD: Mammary gland mass and breast cancer risk. Epidemiology 1992, 3:523-526.

19. Micozzi MS: Cross-cultural correlations of childhood growth and adult breast cancer. Am J Phys Anthropol 1987, 73: 525-537.

20. MacMahon B, Cole P, Brown J: Etiology of human breast cancer: a review. J Natl Cancer Inst 1973, 50:21-42.

21. de Waard F, Trichopoulos D: A unifying concept of the aetiology of breast cancer. Int J Cancer 1988, 41:666-669.

22. Messina MJ, Persky V, Setchell KD, Barnes S: Soy intake and cancer risk: a review of the in vitro and in vivo data. Nutr Cancer 1994, 21:113-131.

23. Maskarinec G, Meng L: A case-control study of mammographic densities among multi-ethnic women in Hawaii. Breast Cancer Res Treat 2000, 63:153-161.

24. Hawaii Medical Service Association Foundation: Health Trends in Hawaii, edn 3. Honolulu, HI: HMSA, 1997.

25. Hawaii Department of Health: Hawaii's Health Risk Behaviors, 1993. Honolulu, HI: Department of Health, Health Promotion and Education Branch, 1995.

26. United States Department of Agriculture: United States Department of Agriculture Nutrient Database for Standard Reference, edn 10. Riverdale: United States Department of Agriculture, 1993.

27. Fleiss JC: Statistical Methods for Rates and Proportions, edn 2. New York: John Wiley \& Sons, 1981.

28. Armitage P: Statistical Methods in Medical Research. Oxford: Blackwell Scientific Publications, 1971.

29. Slattery ML, Boucher KM, Caan BJ, Potter JD, Ma KN: Eating patterns and risk of colon cancer. Am J Epidemiol 1998, 148: 4-16.

30. Maskarinec G, Novotny R, Tasaki K: Dietary patterns are associated with body mass index in multiethnic women. J Nutr 2001, 131 :in press.

31. Kolonel LN, Hinds MW, Hankin JH: Cancer patterns among migrant and native-born Japanese in Hawaii in relation to smoking, drinking, and dietary habits. In: Genetics and Environmental Factors in Experimental and Human Cancer. Edited by Gelboin HV, MacMahon B, Matsushima T. Baltimore, MD: University Park Press, 1980:327-340.

32. Buell P: Changing incidence of breast cancer in JapaneseAmerican women. J Natl Cancer Inst 1973, 51:1479-1483.

33. Ekbom A, Thurfjell E, Hsieh C, Trichopoulos D, Adami H-O: Perinatal characteristics and adult mammographic patterns. Int $J$ Cancer 1995, 61:177-180.

34. Brisson J, Verreault R, Morrison AS, Tennina S, Meyer F: Diet, mammographic features of breast tissue, and breast cancer risk. Am J Epidemiol 1989, 130:14-24.

35. Boyd NF, Greenberg C, Lockwood G, Little L, Martin L, Byng J, Yaffe M, Tritchler D: Effects at two years of a low-fat, high-carbohydrate diet on radiologic features of the breast: results from a randomized trial. J Natl Cancer Inst 1997, 89:488-496.

36. Knight JA, Martin LJ, Greenberg CV, Lockwood GA, Byng JW, Yaffe MJ, Tritchler DL, Boyd NF: Macronutrient intake and change in mammographic density at menopause: results from a randomized trial. Cancer Epidemiol Biomarkers Prev 1999, 8:123-128.

37. Nordevang E, Azavedo E, Svane G, Nilsson B, Holm LE: Dietary habits and mammographic patterns in patients with breast cancer. Breast Cancer Res Treat 1993, 26:207-215.

38. Boyd NF, McGuire V: Evidence of association between plasma high-density lipoprotein cholesterol and risk factors for breast cancer. J Natl Cancer Inst 1990, 82:460-468.

39. Vachon CM, Kushi LH, Cerhan JR, Kuni CC, Sellers TA: Association of diet and mammographic breast density in the Minnesota breast cancer family cohort. Cancer Epidemiol Biomarkers Prev 2000, 9:151-160. 